\title{
Canarias en los orígenes de la Civiliza- ción Atlántica. La conquista del Océano ${ }^{1}$
}

\section{Eduardo Aznar Vallejo}

IEM y R, Universidad de La Laguna

http://doi.org/10.31939/bierehite/2019.05

En la Baja Edad Media asistimos a dos fenómenos estrechamente unidos: la traslación de actividad desde el Mediterráneo al Atlántico y la ampliación del espacio europeo en este mar. Ambos contribuyeron al nacimiento de la llamada Civilización Atlántica, caracterizada por la aparición de un nuevo orden mundial, cuyo motor se encontraba en Europa y cuyo eje geográfico pasó del Mare Nostrum al Océano, como atestigua la cartografía de la época.

Dicho proceso descansará sobre nuevos presupuestos políticos, que favorecerán la concentración de poder en torno a las monarquías nacionales, y servirá para un relanzamiento económico, basado en los conceptos de capitalismo comercial y mercantilismo. Además, servirá para la creación de nuevas sociedades, por la integración en ellas de nuevos pueblos y su carácter ultramarino.

\footnotetext{
1 Esta conferencia nace de la reflexión acerca de trabajos anteriores, a los que remito para los detalles bibliográficos y documentales. Entre ellos, destaco los siguientes: "El encuentro de las culturas prehistóricas canarias con las civilizaciones europeas", $X$ Coloquio de Historia Canario-Americana. Las Palmas de Gran Canaria, Mancomunidad de Cabildos, 1994, I pp. 23-73; "Los itinerarios Atlánticos en la vertebración del espacio hispánico: De los Algarbes al Ultramar Oceánico. XXVII Semana de Estudios Medievales de Estella, Pamplona, Gobierno de Navarra, 2001, pp. 47-82; “Del mar soñado al mar hollado. El redescubrimiento del Océano", Cuadernos del Cemyr, 15 (2007), pp. 175 -195; "Castilla y la frontera atlántica durante la baja Edad Media", La apertura de Europa al mundo Atlántico. Espacios de poder, economía marítima y circulación cultural, (edit. José Ramón Díaz de Durana y José Antonio Munita Loinaz), Bilbao, UPV/EHU, 2011, pp. 39-67.
} 
En este proceso, las Islas jugaron un importante papel, tanto por su posición geográfica, de índole tricontinental; como por el carácter pionero de su evolución, que le confirió en muchos procesos el carácter de laboratorio.

\section{Del mar mítico al mar real.}

Durante la Baja Edad Media se produjo un cambio en la percepción del Océano, cuyo hilo conductor es el repliegue de la interpretación mítica de este espacio geográfico y el consiguiente desarrollo de su conocimiento práctico. La experiencia acumulada durante este proceso afectó a las ideas que se tenían acerca de las características de dicho mar, de las condiciones de navegación en sus aguas, la posibilidad de traspasar sus fronteras, el alcance de sus riquezas y los derechos de explotación sobre las mismas.

El Medievo recibió de la Antigüedad Clásica una serie de opiniones acerca del Océano, que, en general, podemos calificar de contradictorias y alejadas del conocimiento empírico. Tal situación era debida, en buena medida, a su posición periférica en relación con la ecúmene o mundo conocido.

Una visión simplista de la recepción de esta tradición antigua pretende que las ideas que hoy consideramos menos científicas predominaron en los primeros momentos y fueron suplantadas luego por aquellas otras que forjarían la ciencia moderna. Teoría y práctica no fueron siempre de la mano. Marinos y científicos recorrieron vías distintas y, en ocasiones, el peso de las autoridades negaba lo que la experiencia había probado. Otro frecuente error de apreciación consiste en pretender que las ideas clásicas se refieren en exclusiva a determinados lugares del Océano, a aquellos que la historiografía posterior ha fijado. 
Al analizar la apertura del Océano meridional, la primera cuestión que debemos abordar es la relativa al concepto que de este mar tenían los hombres de la Edad Media. La contestación nos conduce, en primer lugar, a su carácter de frontera. A comienzos de la época, Isidoro de Sevilla en De natura Rerum afirma que su anchura es infranqueable para los hombres e inaccesibles los mundos que están más allá.

La extensión de dicho mar era materia de discusión. En cuanto a la primera, la opinión general era, según d’Ailly, que cubría casi las tres cuartas partes de la Tierra, aunque según la opinión de algunos filósofos la cantidad de tierra habitable es mayor y lo que está cubierto de agua es menor de lo que se ha dicho más arriba.

La idea del océano periférico suponía el contacto de los dos extremos de la ecúmene, aunque se discutía acerca de la posibilidad de franquear este espacio. Las dificultades para hacerlo eran, fundamentalmente, la distancia y los peligros del citado mar. Ya hemos visto que la mayoría de los pensadores consideraban dicha distancia como inconmensurable. Sin embargo, algunos otros la consideraban menor o pensaban que era posible la utilización de escalas intermedias. Es más, según Hernando Colón fue esta última posibilidad una de las causas que llevaron a su padre a descubrir las Indias. A ello le movieron los testimonios de marinos portugueses y castellanos sobre hallazgos de nuevas islas y su propia experiencia en el cabo Clark de Irlanda, donde encontró recios vientos de poniente sin que el mar se turbara, lo que demostraba que alguna tierra lo abrigaba hacia Occidente.

El problema de la distancia se veía incrementado por el de la naturaleza de este mar. Para Isidoro se trataba de una materia en ebullición. Ello era debido, según el arzobispo hispalense, a los movimientos alternos, que se producían por su propia respiración 
como ser vivo; por la aspiración de la luna; y porque los astros se alimentaban de las olas. Pierre d'Ailly, por su parte, señala que el Océano baña todas las costas de la Tierra, a las que se acerca y retira con sus movimientos de flujo y reflujo. Al soplar vientos en las profundidades encrespan los mares o los absorben. Tales expresiones parecen deudoras del pulmón marino de Estrabón, quien sitúa este fenómeno cerca de Thule y lo creía capaz de desencadenar los más espantosos vendavales, tanto más terribles cuanto más alejados de las costas de la ecúmene.

A lo anterior hay que sumar las condiciones propias de determinadas regiones. El portulano Pizzigani de Parma contiene una leyenda, frente a las costas de la Península Ibérica, que afirma que más allá de ciertas estatuas el mar es pedregoso. Tal indicación está ligada a la idea del hundimiento de la Atlántida, que dejó todo el mar ciego y atollado, que no se pudo por muchos tiempos navegar. Todavía a fines del siglo XV, el viajero alemán Nicolás de Popievolo habla de Calis Malis, ciudad construida en la costa andaluza entre Lepe y Sanlúcar de Barrameda, que vino a sustituir a la antigua Antioquia, hundida, 20 millas mar adentro, por sus pecados sodomíticos. Otra de esas condiciones particulares era la existencia de regiones anegadas. Las Casas las relaciona con ciertas islas de las Indias, por las cuales aquel compás no se puede navegar, y ha acaecido perderse allí muchos navíos; y recuerda que, según Aristóteles, navíos de Cádiz, salidos al Océano y empujados por vientos subsolanos, fueron a parar a ciertas regiones de la mar donde hallaron la mar cuajada de ovas y hierbas que parecían islas anegadas. Las referencias parecen apuntar al Mar de los Sargazos y, tal vez, al llamado Mar Verde. Éste precedía, con una anchura de ochocientas leguas, al Mar Negro o Mar de las Tinieblas, donde no se remueven en él las hondas, nin corre por el ayre ninguno, ni paresce en el sol ni claridad ninguna, nin es fallada en el ysla poblada nyn despoblada. También es denominado Mar Cuajado porque el agua del non faze movimiento ninguno. Su agua es dulce y nadie conoce su medida. A todos estos inconvenientes hay que sumar los abismos del mar: 
éstos fueron situados por Isidoro más allá de las Hespérides y su autorizada opinión llega hasta Alonso de Cartagena en el siglo XV. La existencia de tales peligros está recogida en la literatura y en la cartografía de la Baja Edad Media mediante una serie de "avisos para navegantes". La mayoría de ellos están vinculados a las columnas de Hércules. A medida que los navegantes penetraban en el Atlántico las estatuas o columnas de Hércules avanzaban hacia el sur y se situaban en los límites de las tierras descubiertas. Diogo Gomes, al referirse a la expedición de Fernando Castro a Canarias, las coloca en el Cabo de Nun, donde Hércules las plantó con la siguiente leyenda: "quien navegue más allá del Cabo Nun, volverá o no". En cambio, el mapamundi de Fray Mauro (1459) indica que he oído contar a mucha gente que aquí/en el golfo Etiópico frente al Cabo Verde/ existe una columna con una mano que muestra una inscripción que prohíbe ir más allá.

El desplazamiento de las imágenes también se produce hacia el interior del Océano. La carta Pizzigani de 1367 sitúa en su límite occidental, a la altura de Madeira y cerca del topónimo Occeanus Magno, la referencia a las estatuas que contenían el "aviso" antes mencionado. Por su parte, La carta anónima veneciana de 1430 insiste en esta localización, pues sitúa en pleno Atlántico la isla de Gades y sus columnas, rodeada de las islas de Colombi, Brasil, Lobos, Porto Santo y Legnami. El descubrimiento de América marca el final de esta traslación, como lo atestigua la adopción por Carlos $\checkmark$ de la divisa Plus Ultra.

La navegación en el Océano encontraba aún otra dificultad. Se trataba de la aplicación a este ámbito de la teoría de los climas, según la cual la región equinoccial o perusta (calcinada) separaba las dos regiones templadas. En la Baja Edad Media el comienzo de la mencionada región tórrida se situaba en el entorno del Cabo Bojador, donde coincidía la dificultad de las corrientes con el temor a no encontrar bases de apoyo en el medio desértico. Y ello, a pesar 
de que dicho punto había sido sobrepasado por las navegaciones catalanas del siglo XIV y de que la información de las caravanas ofrecía detalles sobre la vida al sur del Sahara. La plenitud de los conocimientos trecentistas sobre el África Occidental corresponde al Atlas Catalán (1375). A partir de él se produce un notable retroceso, que sólo comenzará a ser superado tras el paso del Bojador por los portugueses (1434).

Ahora bien, no todo era malo y peligroso en el Océano. Su primera ventaja era contar con numerosas islas, muchas de las cuales ofrecían experiencias maravillosas. Esto era así por la propia condición insular - proclive a lo fantástico-, por su situación remota, y por la tradición recibida de otras culturas.

Para los viajeros medievales, como para muchos historiadores actuales, la existencia de las islas prodigiosas estaba fuera de toda duda y era posible - aunque difícil- encontrarlas. Los autores contemporáneos se han esforzado en dar "realidad" a las islas míticas, asociándolas, por su posición o por el significado de sus nombres, a islas conocidas. El primer método es el empleado por A. Cortesao. Aunque su trabajo resulta útil, por el esfuerzo en ligar situación geográfica y momento del descubrimiento, algunas de sus conclusiones resultan forzadas, al dar valor absoluto a lo que había nacido con carácter simbólico. Así, la Aragavia del Libro del Conocimiento corresponde, según él, a la actual población de Arinaga. En este caso, las objeciones provienen del hecho de que el topónimo no alude a una isla, como es norma en la primitiva cartografía de la región, y de que es desconocido para los redactores de Le Canarien, crónica francesa de la conquista de Canarias, que utilizaron este libro durante la exploración del Archipiélago.

Del segundo método hay abundantes ejemplos en autores canarios, que han buscado identificar las islas del Archipiélago con los 
nombres de las antiguas Afortunadas. Este proceso arranca desde el siglo XIV. En 1337, Petrarca, haciéndose eco de la expedición a Canarias de Lanzarote Malocello el año anterior, se permitió afirmar de las Afortunadas: «de las que tanto por experiencia como por lo que los viajeros cuentan, no tenemos menos información que de Italia y Francia». A partir de entonces, se suceden los esfuerzos por hacer coincidir las islas mencionadas por los antiguos con las que se iban reconociendo.

Ello produjo una amalgama de islas reales e islas fantásticas. En el portulano de Dulcert (1339), por ejemplo, junto a Lanzarote, Fuerteventura y Lobos se representan (a la altura de Madeira) San Brandán, Primaria, Capraria y Canaria. Los siguientes mapas van incorporando nuevos nombres, tanto de los que designan islas que hoy consideramos reales como de los que nombran islas que catalogamos de ficticias. También es frecuente que algunas islas, caso de Canaria o Brasil, aparezcan duplicadas. Este estado de incertidumbre inicial se refleja también en la investidura papal del reino de La Fortuna (1344). En el documento de concesión se citan once islas, pues a las seis habituales se unen Atlántica. Hespéride, Cernent, Gorgona y Goleta, esta última en el Mediterráneo. Durante la segunda parte del siglo XIV el conocimiento de las Canarias y su equiparación a las Afortunadas continuaron avanzando de forma conjunta.

El proceso culminó durante el siglo XV, cuando la cartografía muestra de manera segura el conjunto de las islas y cuando dicha equiparación se impone de forma incontestable. Muestra de esto último son las palabras de Alonso de Cartagena que, al comentar la información de Isidoro sobre las islas de los Afortunados, concluye: de esto se deduce suficientemente que éstas son las islas que actualmente se llaman de Canaria, lo cual está claro por su situación... También se conjetura esto partiendo del nombre, pues algunas de ellas, principalmente las primeras, se llamaban islas de los Afor- 
tunados, según Isidoro. Y todavía hoy la segunda isla de Canaria se llama Fuerteventura, es decir, Fortuna, y así parece que en cierto modo conserva hasta el día de hoy aquel nombre de Fortuna. La cuarta se Llama Infierno... y esta palabra alude al mito de dragón, pues del hecho de que la rodea un mar terrible y zigzagueante, también los poetas en plan novelesco decían que allí había un dragón... por su parte, lo que dice Isidoro de "de cuerpo hirsuto y áspero" concuerda bien con la verdad, pues quizás en todo el mundo no hay incultura semejante ni rudeza o aspereza de costumbres como allí.

Las Hespérides y Górgades, estos dos archipiélagos también tendieron a encarnarse en nuevas realidades geográficas. El segundo de ellos se vinculó rápidamente a Cabo Verde, por su situación frente al Cabo Occidental. El primero, en cambio, tuvo más difícil acomodo. Algunos autores, como Duarte Pacheco Pereira, lo agregan a las islas de Cabo Verde. Otros lo llevan hasta las Indias Occidentales, caso de Fernández de Oviedo, justificándolo en el hecho de encontrarse a cuarenta días de navegación de las Górgades. En medio se sitúan aquellos que no le asignan ninguna ubicación, contentándose con relacionarlo con los anteriores.

Gracias a los viajes de descubrimiento la realidad geográfica fue ganando terreno al pensamiento mítico, aunque sin desplazarlo definitivamente. Es más, el primer impulso de los navegantes fue confirmar lo transmitido por la Tradición. Parte de sus esfuerzos tuvieron éxito y dieron una nueva fisonomía a lo dicho por los Antiguos. Buen ejemplo de ello es la mencionada política de adscribir a determinados lugares los nombres y algunas de las características de los territorios fabulosos. Sin embargo, otra parte del bagaje clásico no pudo ser reelaborado y se conservó como leyenda. La mejor muestra de estos esfuerzos baldíos son las expediciones en búsqueda de tierras e islas que hoy consideramos fantásticas o indicios del predescubrimiento americano. Para el período 14751486, conocemos cinco documentos del rey de Portugal con au- 
torizaciones para descubrir la isla de las Siete Ciudades y otros territorios próximos. Antes, alrededor de 1461, Gonzalo Fernandes creyó avistar una isla al oeste-noroeste de Canarias, pero a causa del mal tiempo no pudo alcanzarla. Le sustituyó en el empeño el duque de Viseu, que envió una expedición para localizarla. A pesar de un nuevo fracaso, obtuvo concesión de la misma por parte de Alfonso $V$, ya que estaba persuadido de su existencia. El propio Colón tuvo conocimiento de este tipo de viajes, en alguna ocasión resuelto con fortuna, como en el caso del descubrimiento de la isla de Flores.

\section{Novedades sociales: nuevos pueblos y sociedad de frontera.}

La dilatación de la antigua ecúmene hizo nacer nuevas categorías en la contemplación europea del "otro". frente a los infieles tradicionales (judíos o mahometanos), que tenían conocimiento de revelación divina y que no habían querido aceptarla, se encontraban los nuevos infieles, que no habían tenido acceso a la misma. Esta constatación planteaba la continuidad del enfrentamiento con el infiel o su sustitución por la aceptación voluntaria del cristianismo y el reconocimiento "ad interim" de sus modelos de organización.

La respuesta al dilema creó dos grandes escuelas. La primera, ejemplificada por Santo Tomás, distinguía entre ley natural y ley sobrenatural, afirmando que los infieles no estaban sujetos a la ley cristiana en aquello que superase a la natural y que la pérdida de gracia por el pecado no privaba de los derechos reconocidos por el derecho natural: libertad, gobierno, propiedad... La segunda, capitaneada por Enrique de Susa (Cardenal Ostiense), identificaba derecho natural y ley revelada, por lo que el incumplimiento de ésta por idolatría, poligamia, pecados contra natura, etc., determina la consiguiente sanción, que priva de los derechos antes mencionados. La última consecuencia de esta argumentación fue la atribu- 
ción de la soberanía de las tierras de infieles al Papa, como vicario de Cristo; y la reacción de los poderes estatales, que, aun admitiendo la "causa fidei", como motor de la expansión, reclamaron la iniciativa y dirección de la misma. En la expansión atlántica, la visión de los nuevos infieles tuvo mayores ocasiones de desarrollo que en los utópicos precedentes asiáticos.

La vinculación de los nuevos espacios geográficos con Europa se realizó de acuerdo con dos modalidades básicas: aculturación espontánea y colonización. La primera pretende influir en las estructuras existentes, pero sin suplantarlas. Podía tratarse de una etapa de transición, como la llamada precolonización del archipiélago canario, o constituir un estado permanente, tal como sucedía en los establecimientos comerciales. La colonización propiamente dicha buscaba la transformación sustantiva y global de la realidad anterior. Ésta sólo triunfó en los archipiélagos, aunque según modelos diferentes. En los de soberanía portuguesa se trató de un proceso de población, dado que no contaban con habitantes aborígenes; mientras que en Canarias se dio un fenómeno de repoblación, al sumarse colonos e indígenas.

La aculturación espontánea utilizó tres vías principales para alcanzar sus objetivos: relaciones comerciales, evangelización y acuerdos políticos. Las primeras fueron la más generales y se basaban en intercambios mediante trueque. Los europeos ofrecían fundamentalmente productos manufacturados (textiles, metalúrgicos), a los que podían añadir alimentos, animales y objetos de valor simbólico. En algunos casos, se trataba de auténtica pacotilla, caso de los anzuelos de pesca, viejas herramientas y cuchillitos intercambiados por los conquistadores franceses en Gran Canaria. El aprecio de los indígenas por determinados bienes, caso de las monedas o de las conchas, se explica por el valor de distinción social o de protección mágica que se les atribuía. Los bienes recibidos podían tener un valor añadido como muestran las copias en hueso de 
objetos metálicos europeos. En Canarias, los bienes recibidos en contrapartida eran productos naturales lorchilla, sangre de drago, madera, ganados, etc.).

La evangelización reforzó los procesos de aculturación, al habituar a los aborígenes a una nueva visión del mundo y de la sociedad. Los mejores resultados se obtuvieron en el archipiélago canario, donde el proceso se desarrolló en dos momentos. Durante el siglo XIV misioneros mallorquines, tanto laicos como eclesiásticos, se instalaron en Gran Canaria. Su presencia se tradujo en relaciones humanas, préstamos materiales e influjos religiosos, con la creación de un obispado misional. Sin embargo, sus comunidades desaparecieron a finales de dicho siglo y fueron sustituidas en el siguiente por otras castellanas. En este caso contaban con el apoyo de las islas ya incorporadas al dominio europeo y su instrumento fue la Vicaría franciscana. Su actuación contó con el concurso de legos aborígenes, y se mantuvo con altibajos hasta la conquista de las diferentes islas, en la que jugó un destacado papel. El ejemplo canario trató de copiarse en el África Occidental, mediante la Nunciatura franciscana de Guinea. Sus resultados fueron escasos, a pesar de que desde 1484 se vieron acompañados por los dominicos instalados en Benin y de que en 1489 se produjo la conversión de un jefe seerer. Las relaciones con el rey del Congo fueron más estrechas, aunque ambiguas y sin consecuencias definitivas. En 1483, en respuesta a una embajada portuguesa, su rey solicitó misioneros. En 1491, el monarca recibió el bautismo y obtuvo el envío de carpinteros, pastores y albañiles. Pero varios años después, el rey apostató para no renunciar a la poligamia y la implantación cristiana periclitó.

Los acuerdos políticos suponían el corolario de estas relaciones, al dotarlas de estabilidad y seguridad. Su establecimiento respondía dos ópticas diferentes. Para los europeos suponían establecer lazos jurídico-políticos, mientras que para los africanos era una for- 
ma de crear relaciones de parentesco, aunque este fuera artificial, no de sangre. También en este caso, los ejemplos más desarrollados son los del archipiélago canario. Los establecidos durante el siglo XIV (mallorquines en Gran Canaria, Lancelotto Malocello y Martín Ruiz de Avendaño en Lanzarotel presentan un carácter más equitativo, aunque conceden un papel rector a los aborígenes. La razón era que acogían a grupos aislados, con supremacía técnica pero muy inferiores en número. Los concertados por los poderes señoriales y luego reales durante el siglo XV también podían ser rotos por ambas partes, aunque favorecían a los castellanos, que contaban con presencia permanente en otras islas del Archipiélago y cuyos recursos económicos tenían un gran atractivo para las poblaciones insulares. La mayoría de ellos terminaron favoreciendo la conquista, al crear "bandos de paces", que colaboraron con los colonizadores a cambio de apoyo frente a los restantes grupos indígenas. Tras la conquista, dichos pactos se extinguieron y dieron paso a una única organización política, netamente europea.

La sociedad constituida tras la conquista bascula entre los principios heredados de la metrópoli y los propios de una sociedad "de frontera". La jerarquización vivida en los lugares de origen, basada en el linaje y en el dominio señorial de hombres y territorios, se articula en los nuevos territorios alrededor de la valía personal y la liquidez monetaria. Esto no excluye que a la larga el nuevo grupo dirigente, formado por los capitanes de la conquista y los financieros de la misma, tendiera a convertirse en auténtica nobleza mediante la amortización de tierras, la obtención de cargos concejiles y la arrogación de privilegios fiscales, primero a título personal y luego hereditario. El desarrollo administrativo, con su cohorte de letrados; el avecindamiento de mercaderes y la aparición de nuevos propietarios, gracias a los repartimientos de tierras; favorecieron la aparición de grupos "medios". Por debajo de ellos se situó el campesino repoblador, cuya suerte varió desde quienes recibieron suficientes tierras y tuvieron los medios materiales y humanos para ponerlas en cultivo hasta quienes obtuvieron escasa cantidad o hu- 
bieron de ceder su parte por no poder cultivarla. No faltó, incluso, un proletariado, que no recibió bienes por su tardía incorporación a la colonización y que hubo de contratarse como asalariado. El último escalón del orden social estuvo representado por los esclavos de diverso origen y libertos que de ellos surgieron.

La paulatina estratificación de la sociedad al modo metropolitano no terminó con otras características de las sociedades de frontera. Es el caso de la debilidad del núcleo familiar, producida por la dispersión geográfica de sus miembros y por la proliferación de fórmulas irregulares de convivencia (bigamias, concubinatos y otras). También lo es la desvertebración de las sociedades aborígenes y el desarraigo de los esclavos africanos y, en menor medida, de los colonos europeos.

Otro rasgo del carácter fronterizo de la nueva sociedad era el importante proceso de aculturación operado en su seno. El mismo tuvo una orientación más cultural que política, por lo que los europeos asentados en territorios sujetos a otra nacionalidad apenas conocieron problemas de integración. Los aborígenes y los esclavos africanos, en cambio, hubieron de adaptarse a las nuevas costumbres. Los medios para conseguirlo fueron la cristianización, la adopción de nuevas actividades económicas y el establecimiento de lazos familiares.

La primera fue entendida más como sometimiento ritual a la divinidad que como conversión interior, lo que a la larga creó problemas de pervivencias de las antiguas costumbres y de falta de formación religiosa. Así lo atestiguan los informes del Santo Oficio, aunque su corrección se presenta como asequible por provenir de poblaciones mayoritariamente paganas, no infieles.

La promoción económica estaba ligada a la práctica de la agricultura y de la ganadería estante, que favorecían la sedentarización y, 
como en el caso anterior, la convivencia con los europeos. En algunos casos, también se produjo la adopción actividades artesanales, aunque aquí el mayor número de concernidos provino del grupo de los esclavos manumitidos, que habían aprendido dichos oficios mientras trabajaban para sus amos.

Las uniones conyugales entre aborígenes y repobladores se explican por la conveniencia de unir a los grupos dirigentes de ambos grupos y, sobre todo, por el alto índice de masculinidad existente entre los colonos. Conviene advertir que algunas de estas relaciones no tuvieron la consideración de matrimonios legítimos, limitándose al de matrimonios "de facto" o a concubinatos.

El carácter "fronterizo" se expresaba también en un menor peso de los valores imperantes en la metrópoli. Las evidencias acerca de este espíritu son diversas: oposición a la constitución de cofradías "de limpios", papel de libertos, homicianos y otros grupos marginales en la nueva sociedad, dificultades a la implantación de la Inquisición, ... Ello no era impedimento, no obstante, para que existiera un cierto mimetismo en el cuerpo social. El mismo tendía, conforme avanzaba la colonización, a la recreación del orden vivido en los lugares de origen.

Las fórmulas para conjurar la falta de vínculos familiares eran diversas: la protección de un poderoso o de un convento, el apoyo de los connaturales, la pertenencia a una o varias cofradías ..., aunque todas se articulaban sobre un mismo principio: la creación de una solidaridad suprafamiliar. Las más frecuentes eran las que descansaban sobre grupos, no sobre individuos o instituciones. En Canarias, no existían cofradías profesionales, por lo que la totalidad de las mismas estaban abiertas a personas de cualquier origen y condición. Además, era frecuente la pertenencia simultánea a varias de ellas. Sus funciones sociales eran fundamentalmente 
asistenciales y caritativas, por lo que se cuidaban de socorrer a sus miembros en los momentos de necesidad y de acompañarles a la hora del entierro, al tiempo que solían regentar un pequeño hospital para ayudar a los menesterosos.

La ayuda de los coterráneos tenía gran importancia, aunque por razones diversas en cada grupo. En el caso de los aborígenes, se orientaba a la defensa de la persona, bienes y libertad de los miembros de la comunidad; mientras que, en el caso de los integrantes de las colonias mercantiles, buscaba la defensa de sus privilegios comerciales; y en el de los africanos emancipados, la posibilidad de reunirse para el mantenimiento de algunas de sus costumbres. Conviene señalar que las comunidades de origen europeo tenían una existencia anterior a su implantación en el Archipiélago; mientras que las de los aborígenes terminan de formarse en el transcurso de la colonización, al irse borrando las antiguas diferencias tribales y de estatuto jurídico; y las de los africanos nacen de la visión europea "del otro", que difumina las antiguas agrupaciones étnicas y culturales (bereberes, jalofes, mandingas...), para recrear dos grandes grupos atendiendo básicamente al color de la piel: moros y guineos.

En el caso de los naturales, el signo más evidente de esta solidaridad era la existencia de "procuradores", que canalizaban ante las autoridades las reclamaciones por ataques a su libertad, libre disposición de sus bienes, etc. Su extracción correspondía a personas de alcurnia en la antigua organización aborigen y a gentes con alto grado de conocimiento de los usos y costumbres castellanos. La actuación de los mismos resultaba odiosa a los colonizadores por utilizar en su pro el ordenamiento legal castellano, lo que constituye un claro precedente de la figura de los indios ladinos. Inicialmente, su representatividad abarcaba a uno o varios bandos, normalmente de los que habían pactado con los conquistadores; aunque con el tiempo fueron adquiriendo un papel a nivel insular e 
incluso suprainsular. Otras muestras de apoyo entre los indígenas se daban en el terreno laboral, en el que eran frecuentes diversas fórmulas de asociación o de contratación preferente; y en el de las relaciones familiares, en el que abundaban los enlaces y la asunción de labores de tutela, padrinazgo, etc. En estos casos también asistimos a la progresiva ampliación de lazos entre diferentes grupos de la población autóctona.

La imagen más patente de la solidaridad entre europeos era la creación de capillas privativas. Éstas evidenciaban, a través del culto al santo patrón y del enterramiento en común, la existencia de lazos comunes, que se desarrollaban en la defensa de sus intereses comerciales, en los abundantes matrimonios dentro del grupo, en la responsabilidad colectiva ante los requerimientos de las autoridades...

En el caso de los africanos negros (guineos), la principal vía para canalizar la solidaridad interna era la creación de una cofradía, que les permitiese mantener algunas de sus costumbres y la labor asistencial entre ellos. Tal recurso no consta para los norteafricanos (moros), cuya cohesión se basaba en la vida interna de la comunidad, a fin de preservar su modo tradicional de vida sin despertar recelos. Por ello, la única manifestación pública del grupo se produjo en los procesos incoados para su expulsión, en los que pidieron y obtuvieron su paralización.

El resultado final fue una sociedad nueva, aunque con claras reminiscencias de las metropolitanas, especialmente de la castellana y de la portuguesa. Las concomitancias con estas últimas se deben tanto al origen de los repobladores como a las características del cuerpo social. En el primer caso, los repobladores importaron de ambos reinos sus usos y costumbres. En sus aspectos políticos predominan los del país que ejercía la soberanía sobre el territo- 
rio, pero en los restantes (técnicas agrarias, religiosidad, vida cotidiana, etc.) se evidencia la heterogeneidad, que desciende hasta niveles regionales.

La importancia numérica y la relevancia social de dichos grupos no marchaban necesariamente al unísono. En unos casos, ésta se veía frenada por el hecho de no formar parte del grupo rector de la colonización, caso de los portugueses. En otros, la misma se veía aumentada por su importancia en el sistema productivo. El ejemplo arquetípico de esta situación es el de las colonias mercantiles, cuyo escaso número era compatible con un fuerte protagonismo económico. Éste nacía de su papel de dinamizadores de la economía canaria y de su riqueza mueble, que les confería, en una región carente de capitales, una amplia capacidad inversora. De ella se derivaban la posibilidad de adquirir tierras, realizar operaciones crediticias, concertar ventajosos enlaces matrimoniales..., todo lo cual redundaba en su promoción social.

Desde esta perspectiva, la situación de las comunidades aborígenes era ambivalente, dado que su concurso podía garantizar el mantenimiento de gran cantidad de aprovechamientos, pero su número y, sobre todo, su arraigo era vistos como un peligro para el nuevo orden. El tiempo terminará jugando a favor de la primera posición. Inicialmente, la integración afecta a los elementos más permeables al influjo europeo. Esto es: aquellos que habían vivido fuera de las Islas y, especialmente, quienes habían regresado a las mismas con la condición de "conquistador". Posteriormente, gracias a la generalización de los usos y costumbres de los repobladores. Este cambio paulatino irá trasladando el problema de los esclavos alzados a otras comunidades, especialmente a la de los berberiscos, que se veían espoleados por las posibilidades de huida al vecino continente. Vencidas las reticencias y anulados, por tanto, los sucesivos proyectos de expulsión, los naturales se convirtieron en un importante elemento de la sociedad canaria. Hay 
que advertir, sin embargo, que un hecho llamado a tener gran importancia en el campo del imaginario colectivo, cual es la adopción de lo aborigen como signo diferencial, es posterior al período que historiamos. Dicho proceso debe situarse a fines del XVI, cuando la colonización estaba plenamente asentada y las diferencias de origen se encontraban muy atenuadas. Testimonio precoz de este espíritu es el contenido en la obra de Antonio de Viana Antigüedades de las Islas Afortunadas de la Gran Canaria, conquista de Tenerife y aparición de la imagen de Candelaria, que señala "sentí como hijo agradecido, las injurias que a mi patria hizo el extranjero a título de celebrarla, agravió a los antiguos naturales en muchas varias opiniones que afirma, obscureciendo su clara descendencia, y afeando la compostura de sus costumbres y república". Tales opiniones no fueron inicialmente unánimes, como prueban los pleitos que hubieron de mantener los descendientes de los aborígenes del bando de Güimar en defensa de su derecho a cargar la imagen de la Virgen de Candelaria, frente a las pretensiones de los regidores de la isla y los dominicos de su santuario.

\section{Novedades políticas: estado moderno y monarquías nacionales.}

El término Estado Moderno designa la forma de organización política de las naciones europeas entre los siglos XIII y XVIII, intermedia entre el Estado Feudal y el Estado Constitucional. Su desarrollo corre paralelo al del sistema jurídico de la recepción del Derecho Común y a la propagación del pensamiento aristotélico. Su forma coincide con los Estados-Nación, caracterizados por el triunfo del vínculo de naturaleza política, una clara delimitación del ámbito territorial del poder y la aparición de sentimientos patrióticos. Su motor es la figura del monarca, dotado de un poder que aspira a ser absoluto, que dirige la centralización de los medios de poder políticos-administrativos y asume el monopolio del uso legítimo de la fuerza para asegurar la paz social y la defensa frente al exterior. 
Además, consigue la integración de las elites de poder en el seno del nuevo estado. Las tierras ultramarinas constituyeron un campo abonado para su desarrollo, dado que todo estaba por construir y el peso de la tradición era más tenue.

La colonización no se limitó a la reserva del territorio. Exigió, por contra, un proceso de conquista y ocupación del territorio. La tarea fue confiada inicialmente a particulares, mediante la creación de señoríos en Castilla y de capitanías donatarias al servicio de miembros de la casa real en Portugal. La autonomía de estas fórmulas fue decreciendo con el tiempo, conforme la monarquía aumentó su participación en la vida del reino.

La actuación de los monarcas se vio favorecida por el coste creciente del gasto militar y por el relevante papel de los archipiélagos en la pugna luso-castellana por el Atlántico. Los reyes emplearon para tal fin parte sus tropas permanentes, las contribuciones de los concejos de realengo y la colaboración de compañías mercantiles, que adelantaron fondos con la seguridad de resarcirse con rentas reales o con la participación en el botín obtenido. Terminada la conquista, los reyes favorecieron el poblamiento de los nuevos territorios mediante un generoso reparto de tierras y un régimen fiscal más benigno.

La implantación de esta nueva soberanía política se enmarca dentro de dos procesos propios de la Baja Edad Media: el agotamiento de las ideas y poderes de tipo universal, en favor de los nacientes estados nacionales; y el auge creciente de los países atlánticos frente a los mediterráneos. Ello explica que las distintas etapas de la expansión se hayan emprendido desde Castilla y Portugal, con una creciente participación estatal. El resultado final es la menor intervención del Papado, que pasa de dispensador de soberanía a árbitro entre los diferentes reinos e impulsor de la evangelización, 
a pesar del mantenimiento de algunas reivindicaciones puramente teóricas. Dentro de esta dinámica, los diferentes Estados utilizan diversos procedimientos, desde los diplomáticos a los militares, para imponer su autoridad y sólo al final acuden al Papado para resolver sus diferencias o sancionar sus acuerdos. La soberanía pasa, por tanto, por una serie de tratados de partición, que se inspiran en los que habían regulado la Reconquista peninsular.

En Canarias, las distintas etapas de su primera historia traducen el peso creciente de la monarquía. Durante la fase de Precolonización (S. XIV) la monarquía se limitó a reclamar dicho espacio para sus súbditos y a lucrarse con una parte de lo obtenido por estos. Durante la Época Señorial la acción regia se incrementa progresivamente. En el período francés (1402-1418) el rey aceptó la enfeudación de Jean de Bethéncourt y la creación de un señorío inmune. La autonomía de este régimen es visible, más que en el título de rey de su titular - puesto que el Archipiélago había sido elevado a la categoría de reino desde la investidura papal a don Luis de la Cerda-, en el cúmulo de prerrogativas que poseía y que lo independizaba en materias de derecho, justicia, moneda... del resto del Reino. Sin embargo, no todas estas prerrogativas llegaron a ejercerse, quedando pesas y medidas, moneda y otros aspectos dentro de la órbita castellana. Además, la exención de quintos sobre las mercancías enviadas desde las Islas supuso la inclusión del Archipiélago en el marco fiscal general del Reino, dado que sus productos sólo debían pagar almirantazgo y alcabalas como cualquier otra ropa de mercaderes. Otro terreno en el que la influencia castellana quedó asegurada fue el eclesiástico, ya que la diócesis de Rubicón fue constituida como sufragánea de Sevilla y sus titulares fueron castellanos, provistos a petición de los Reyes de Castilla.

Los señores castellanos, por el contrario, no basan su poder en un "pacto feudal" con el monarca sino en una "delegación jurisdiccional" del mismo. Ello queda patente en l aplicación en el Ar- 
chipiélago de las leyes generales del Reino y de un derecho local de raigambre andaluza. Lo mismo sucede en la administración de justicia, en la que el monarca se reserva ciertos casos y un amplio recurso de alzada. Y otro tanto ocurre en la intervención regia en el territorio, en la que se produce un notable acrecentamiento visible en las confirmaciones de la transmisión del señorío, en el secuestro de las islas sobre las que existían litigios de titularidad, en el restablecimiento de los derechos señoriales tras la revuelta gomera de 1488 y en la reserva sobre las islas mayores.

La llamada Época realenga tuvo su arranque en 1475, momento en que la revuelta antiseñorial en Lanzarote y el inicio de la guerra luso-castellana dieron pie a la intervención directa de la monarquía. Paralelamente y como muestra de que la política de afirmación estatal no era coyuntural, se produjo el relevo de los señores al frente de la expansión africana. El primer paso en esta dirección fue la pesquisa encomendada a Esteban Pérez de Cabitos, cuyo contenido fue examinado por el Consejo, con vistas a fijar la titularidad del señorío y el derecho de conquista. En ambos extremos el resultado fue favorable a los señores, aunque se reconoció el derecho de los monarcas a ocuparse de la conquista mediante una compensación económica.

En el plano administrativo, la colonización realenga supuso la intervención directa de la monarquía en tres de las siete islas y una mayor presencia de la misma en el conjunto del Archipiélago. Sus oficiales tenían cierta intervención en el conjunto de la región en materia de defensa e imposición fiscal y la Audiencia, que tenía competencia en todas las islas, tenía residencia en una de realengo.

En 1526 se creó la Audiencia de Canaria, que debía regirse por el orden e manera que tienen e guardan los jueces de los grados de Sevi- 
lla. Esta vinculación se acrecentó en 1556, al reservarse al tribunal sevillano el conocimiento en alzada de los asuntos procedentes de las Islas, que hasta entonces competía a la Chancillería granadina. La excepción de esta política se refiere a los asuntos de hidalguía, que siguieron viéndose en la citada chancillería, por carecer el tribunal hispalense de sala competente.

La fundación de las audiencias obedecía al claro propósito de impulsar el poder real. No es, por tanto, un proceso privativo de las regiones ultramarinas, aunque sus problemas de comunicación lo hicieran especialmente aconsejable. La prueba de lo anterior lo encontramos en la institución de la Audiencia de Galicia, cuyos orígenes arrancan de la creación la gobernación de dicho reino en 1480 y alcanzan plenitud en las dos siguientes décadas. En este caso se trataba de consolidar la pacificación de la región, poniendo coto a los poderes señoriales. En Canarias la Audiencia era común a todas sus islas, lo que permitía englobar a las de señorío. Además, se vinculaba a la isla de Gran Canaria, creando un contrapeso a la gobernación vitalicia de Tenerife y La Palma.

A pesar de lo referido hasta aquí, las unidades básicas de la administración eran los concejos municipales. Sus competencias iban desde el campo judicial hasta la defensa, pasando por la sanidad, la instrucción, el urbanismo y un largo etcétera.

Los concejos de la nueva frontera son hijos de su tiempo, por lo que presentan dos características propias del mismo: el predominio aristocrático en su gobierno y la menor autonomía frente al poder real.

En el primer caso, conviene recordar que tales concejos se crearon según el sistema de concejos cerrados o regimientos. Su 
carácter restringido se vio reforzado el sistema de designación de representantes y por la duración del mandato de estos. En el nombramiento de regidores, la norma consolidada a través del tiempo fue la designación real. La representatividad anterior no era mucho mayor pues se basaba en elecciones indirectas, mediante el sistema mixto de compromisarios y suerte, lo que tendía a la perpetuación de determinados grupos. Además, los cargos tendieron a hacerse vitalicios e incluso hereditarios, mediante el ardid de la renuncia en vida de su titular. Efectos añadidos de esta política fueron el aumento del número de regidurías y la compraventa de las mismas.

La consolidación política de las oligarquías locales terminó por constituir un peligro para la monarquía que las había apoyado. La respuesta de la Corona consistió en imponerles medios de control y variar el marco legal por el que se regían.

En el primero de dichos campos el elemento primordial fue el establecimiento de representantes regios en la presidencia de los concejos. Aunque se trata de un proceso común al conjunto de la Corona, en las zonas de frontera alcanzó un nivel más destacado. Buena prueba de ello es la consolidación en Canarias e Indias de la figura del gobernador. Eran esencialmente representantes de la Corona en la vida concejil, por ello representan ciertas similitudes con otros cargos de idéntica finalidad como los gobernadores del reino de Galicia y Marquesado de Villena o los corregidores y asistentes de otros concejos castellanos. Esto no impide que posean características propias que los distinguen. En cuanto al ámbito de acción, hay que reconocer que las islas, al igual que Galicia o el Marquesado de Villena-, necesitaban una autoridad extraordinaria que pusiese en marcha la incorporación efectiva a la Corona y salvase el alejamiento de los órganos centrales de decisión. Ahora bien, los gobernadores insulares no coexisten con los corregidores como sucede en los mencionados territorios, sino que ellos mis- 
mos ejercen tales funciones. Su designación correspondía a los monarcas, quienes se reservaban su mantenimiento por el tiempo que estimaran oportuno. Por lo tanto, y al igual que otros gobernadores, no están sujetos al principio de anualidad que regía para los corregidores. Como excepcional hay que considerar el caso de don Alonso Fernández de Lugo, que obtuvo vitaliciamente la gobernación de Tenerife y La Palma, merced luego extendida a uno de sus sucesores. Su actuación era fiscalizada mediante juicios de residencia, celebrados sin plazo fijo y que incluían también al gobernador vitalicio.

A grandes rasgos, sus competencias coinciden con los capítulos dados para gobernadores, corregidores y jueces de residencia de todo el reino por los Reyes Católicos e 1500, los cuales también estaban obligados a guardar. Ahora bien, algunas prerrogativas les son propias, muy particularmente la de repartir tierras a los nuevos pobladores. La administración de justicia era una de las principales misiones del gobernador, de ahí que se le denominase «justicia» o «justicia mayor». Los gobernadores eran, además, la máxima autoridad militar. Los amplios poderes que les fueron otorgados, planteó la paradoja de que la Corona hubiese de vigilar a sus representantes mediante tenientes de gobernador, aparte de los preceptivos juicios de residencia. La designación de jueces de residencia se realizaba sin plazo fijo y era prerrogativa del monarca. La duración de su mandato no se limitaba al tiempo asignado a las residencias en la ley de las Cortes de Toledo, sino que acabado éste, seguía detentando las varas de justicia hasta que el rey nombrase nuevo gobernador o juez de residencia. Por esta razón, su figura se confunde con la del gobernador, ya que éste solía ser el encargado de tomar la residencia a su antecesor.

El alcance del derecho local en la Baja Edad Media sufrió un duro retroceso, acorde con el proceso de centralización monárquica. Si durante la Plena Edad Media los fueros locales contenían lo sustancial 
de la regulación de la vida de las personas y comunidades, no sucede lo mismo a partir de entonces. La prelación a favor de las leyes generales del reino hará que mucho de los antiguos preceptos pierdan vigencia. Por eso, cuando durante este período se promulguen nuevos fueros, como el otorgado en 1494 a Gran Canaria, tendrán un alcance limitado. Esta denominación particular no es incompatible con la pertenencia a un conjunto de mayor amplitud, lo que explicaría que sea idéntico al otorgado para Baza y las constantes alusiones a que la isla estaba poblada a fuero de Granada y Sevilla. En el supuesto que determinado asunto no estuviese contemplado en el fuero o que éste no existiese, la norma a seguir eran las provisiones reales que sobre tal caso poseyese el cabildo, que constituían un fuero implícito y que en algunas ocasiones recibía tal denominación.

La Corona aprovechó la coyuntura para influir en el nuevo derecho local, uniformizando las bases del mismo. El derecho local canario está emparentado con el andaluz que tiene como modelo último el fuero de Toledo. Las distintas adiciones que éste fue sufriendo hizo variar su nombre: fuero de Sevilla, de Córdoba, de Niebla..., pero conservó un fondo común. Los reyes siguieron la misma política en cuanto a las ordenanzas municipales, que eran la concreción de las normas de derecho local para cada uno de los concejos. Al igual que en el caso de los fueros, el modelo utilizado para su confección fue el andaluz, en especial las ordenanzas de Sevilla.

El encuadramiento político de los territorios recién incorporados se realizó también a través de los cuadros administrativos de la Iglesia. Aunque la política regalista tenía una larga tradición en Castilla, será en este momento y en estas regiones cuando alcance su máximo medieval. La afirmación del poder regio y la necesidad de evangelizar y encuadrar religiosamente a nuevas poblaciones explican este hecho, cuya máxima manifestación será el Real Patronato.

En el caso canario, dicha política existe desde los inicios de la colonización. Su primer paso se dio en la erección del obispado de 
Rubicón en 1404, al constituirse dicha iglesia como sufragánea del arzobispado hispalense, lo que facilitó su influjo. El momento culminante del mismo se produjo en 1485, al presentarse al arzobispo la bula para trasladar la sede a Gran Canaria y promulgarse de acuerdo con éste los nuevos estatutos. La muestra más evidente de dicha vinculación era la apelación para el arzobispo de las sentencias de los tribunales episcopales.

En diciembre de 1486 se produjo un cambio sustancial en la vida de la iglesia canaria, al ser declarada de patronato real, en unión de las de Granada y Puerto Real. El patronato regio se manifestaba en dos prerrogativas principales el pase regio y la presentación de dignidades. La primera concedía al monarca la fiscalización de la legislación pontificia antes de su aplicación. La segunda reservaba al rey la designación de titulares para los distintos beneficios.

Tres años más tardes culminó el proceso de intervención regia en el obispado canariense, al obtener las tercias reales de sus diezmos. Su percepción sólo se realizaba en las islas de realengo, incluida el señorío episcopal de Agüimes. Su extensión al resto del Archipiélago no logró consolidarse, debido a la no participación de la Corona en la conquista

\section{Novedades económicas: capitalismo y mercantilis- mo.}

La expansión ultramarina supuso también un importante factor de crecimiento económico, al ofrecer a la sociedad europea abastecimiento para sus necesidades y nuevos mercados para sus productos. El enriquecimiento derivado de dicho proceso favoreció a las monarquías, que desarrollaron políticas mercantilistas a favor de sus reinos y de sus rentas. 
El Estado buscó en los descubrimientos geográficos no sólo una expansión de su poder y soberanía, sino también un sustancial aumento de sus rentas, imprescindible dadas las crecientes exigencias de la política interior y exterior. La navegación castellana en el Atlántico permitió a la monarquía la obtención de nuevos ingresos en calidad de regalías. Eran éstos: la orchilla de África y Canarias, las conchas del Archipiélago y los arrendamientos sobre los caladeros africanos. La Corona también pretendió reservarse el comercio de la zona. En este proyecto hay que distinguir dos momentos: el correspondiente a la guerra luso-castellana y el posterior a la misma. Durante el primero, reclamó la conquista de “África y Guinea" y la regulación de todas las actividades que en ellas se realizasen. Acabada la guerra, los monarcas se reservaron el control comercial sobre la zona de soberanía castellana. El primer y principal foco de acción fue Santa Cruz de la Mar Pequeña. En el tráfico comercial de esta factoría podemos distinguir dos tipos de operaciones: las realizadas por representantes de la Corona y las emprendidas por particulares con licencia, a cambio de la mitad de los beneficios.

Canarias recibe de su período fundacional el carácter de economía que aúna un sector dedicado a garantizar la subsistencia con otro especializado y orientado hacia el exterior. También es éste un logro paulatino, cuya obtención ocupa la práctica totalidad del período que consideramos.

Durante el siglo XIV existió una relación económica con el exterior, aunque su base era el drenaje de productos ofrecidos por la economía aborigen o fruto de la recolección. Durante el siglo XV se puso en marcha una nueva economía productiva, si bien estaba orientada al autoabastecimiento y se movía dentro de límites muy estrechos. La misma preservó la tradición aborigen de ganadería menor, dedicada a la obtención de alimentos y materias primas artesanas. En ella, el sistema de cría siguió siendo extensivo, de 
ahí la importancia de la suelta de animales, pero se adoptaron nuevos usos alimenticios, como el consumo de animales muy jóvenes, propio de regiones donde el abastecimiento básico estaba asegurado. Al tiempo se introdujo el ganado de trabajo, aunque en sus especies menos costosas, caso del asno. El ganado mayor estaba ligado a la agricultura, caracterizada por su escasa producción y por su dedicación a productos poco exigentes, como la cebada, o extraordinarios, como algunos frutales y hortalizas. El déficit productivo, tanto alimenticio como artesanal, se cubría con importaciones, en su mayoría andaluzas (trigo, vino cerámica). Para poder pagarlas se contaba con algunos productos ganaderos y de recolección (especialmente orchilla) y, de manera más significativa, con los beneficios de las cabalgadas y rescates en las islas aún por conquistar. De estas últimas procedían sangre de drago, orchilla, madera, ganados y, sobre todo, esclavos.

El gran cambio económico en la dirección anunciada se produjo a partir del último cuarto del siglo XV, al colonizarse las islas más ricas y aumentar la vinculación con el exterior. La intensificación de la producción agraria, en la que la ganadería se subordina a la agricultura, permitió el abastecimiento de la población en años y condiciones normales. Además, dio lugar a exportaciones, tanto en el caso de los excedentes de cereal como en el de los cultivos expresamente orientados hacia el mercado exterior. Entre estos últimos hay que destacar al azúcar, no tanto por la superficie a él dedicado como por su repercusión en la dinamización de la economía canaria. Su concurso suponía un gran poder de compra en mercados exteriores y la llegada de capitales. Lo primero permitía un mejor abastecimiento de productos deficitarios, especialmente artesanales; mientras que lo segundo se traducía en la vinculación a los grandes circuitos comerciales del momento. Estos intercambios con las zonas más desarrolladas de Europa, basados en la permuta de materias primas y productos naturales por productos manufacturados, se completaba con procesos de redistribución hacia África y América. Esto último contribuía, a su 
vez, a incrementar la oferta del mercado canario de cara a sus proveedores.

Llegamos así a la constitución de una economía dinámica, en el sentido de que iba más allá de la mera satisfacción de las necesidades básicas, aunque se encontraba muy ligada a los vaivenes de los mercados internacionales.

La proyección exterior del Archipiélago comenzó en dirección a África, tanto para la apertura de nuevas vías de exploración en el Continente como para el aprovechamiento de las áreas próximas a Canarias. La primera razón es la más antigua y se desarrolló a partir de dos hechos patrocinados por don Enrique el Navegante: la colonización del archipiélago de Madeira y el paso del Cabo Bojador en 1434. Estos hechos situaban a las Islas a medio camino de los dos polos de interés lusitanos. La segunda causa se esboza una decena de años después, al compás de la controversia por el espacio comprendido entre los cabos de Aguer y Bojador, aunque no se consolida hasta bastantes años después, ya que sus aprovechamientos esenciales (cabalgadas y pesquerías) podían realizarse con menos riesgo en las islas canarias aún por conquistar. La situación varía a comienzos del último cuarto del siglo XV, al iniciarse la conquista monárquica de las islas todavía insumisas. El símbolo más evidente de este cambio es la construcción en la costa africana de la torre de Santa Cruz de la Mar Pequeña, primero por iniciativa señorial y luego real.

El final de esta evolución, que colocaba al mundo canario en la que iba a ser su posición distintiva: un enclave europeo en el camino hacia África y América; se produce a fines del siglo XV. Los libros de derrotas náuticas, tanto castellanos como portugueses, son unánimes al destacar su papel en las navegaciones a las Indias Orientales y Occidentales. A las ventajas geográficas se unirán 
posteriormente los lazos humanos, los intereses económicos y las especificidades administrativas.

La privilegiada situación de Canarias dentro de las rutas comerciales de África y América propició la idea de incluir su comercio, al igual que el de las Indias o Berbería, dentro del régimen monopolístico de la Casa de Contratación. Sin embargo, este proyecto no prosperó y el comercio canario quedó abierto a todas las iniciativas, aunque la legislación que lo regulaba presentaba variantes respecto a la general del reino.

La necesidad de abastecer Las Indias reportó a las Islas una serie de privilegios, que significaron su participación en el monopolio sevillano. Esta participación suponía el envío de mercancías desde las islas, con el único requisito de remitir certificación a la Casa de Contratación. Este régimen comenzó en 1508, cuando se autorizó a los naturales del reino enviar las mercancías que quisieren, con tal que las registrasen ante las personas nombradas por los oficiales de la Casa. Ignoramos la duración de concesión tan generosa, pero no debió ser demasiado extensa, debido a la presión de los mercaderes radicados en Sevilla.

Desde finales del siglo XV existía una segunda forma de participación en el monopolio, cual era el embarque de mercancías en las islas con certificación de la Casa. Esta modalidad ofrecía menos posibilidades para las Islas, que veían supeditados sus intereses a los de los mercaderes hispalenses; pero su continuidad, asegurada por la conjunción de intereses de la Corona y de los círculos comerciales sevillanos, representó una vía para la salida de productos no desdeñable.

La proximidad del archipiélago a la costa africana convirtió a las Islas en base de penetración en la fachada atlántica de dicho conti- 
nente. En esta penetración hay que distinguir entre el sector comprendido entre los cabos de Aguer y Bojador, y los que se extendían al norte y sur de estos puntos. La diferencia entre ellos consistía en que en el primero la Corona castellana organizaba su vida comercial, mientras que los restantes permanecieron dentro de la órbita portuguesa. Los intercambios con estos se realizaban mediante acuerdos entre ambas coronas, destacando los concertados para el envío de conchas de Canaria y paños de colores a Guinea para trocarlos por oro.

Las acciones militares desarrolladas en las regiones atlánticas eran, fundamentalmente, las cabalgadas. Las cabalgadas también contaban con tradición anterior, aunque ahora contaron con condiciones más propicias. La razón de esta mejoría era que el objetivo fundamental de las cabalgadas era el ataque contra aduares nómadas, que en las regiones del sur eran muy abundantes y carecían de la ayuda de fortificaciones o tropas regulares para su defensa.

La pesca en las costas africanas tenía una larga tradición en Castilla y Portugal. Por esta razón, la única novedad fue el continuo descenso hacia el sur, que terminó por alcanzar las pesquerías de Guinea, es decir: las situadas al sur del Cabo Bojador. La distribución de las zonas de faena se adecuó al reparto político entre Castilla y Portugal, aunque permitiendo la actividad del otro país. Así sucedió en el reino de Fez, donde portugueses y castellanos compartieron su trabajo. En la mayoría de las ocasiones lo hicieron de forma amigable, gracias a los acuerdos entre ambas coronas. A pesar de ello, no faltaron algunos ataques por parte de los marineros lusitanos. Entre los cabos de Aguer y Bojador la iniciativa correspondía a los castellanos, aunque existieron tensiones con los portugueses en los dos extremos de la zona. Los principales caladeros se encontraban, aparte de en los dos puntos ya mencionados, en San Bartolomé y Mar Pequeña. Sus principales protagonistas fueron los andaluces y canarios. Las pesquerías al sur del Cabo Bojador 
caían dentro de la jurisdicción lusitana, aunque consta la presencia castellana en las dos más rentables, las del Angra de los Rubios y la del Angra de los Caballos.

Al comercio ordinario practicado con los reinos sedentarios del norte, se fue añadiendo el trueque con las regiones meridionales, primero de manera inestable y luego fija. La mejor evidencia de este cambio es la construcción de fortalezas en enclaves privilegiados (Santa Cruz del Cabo de Aguer, Santa Cruz de Mar Pequeña, San Jorge de la Mina, etcétera). Los productos requeridos por los europeos eran aquellos que tradicionalmente habían llegado a los puertos del Magreb por medio de rutas caravaneras: oro, esclavos, especias y otros similares. Las mercancías enviadas a cambio eran productos artesanales y alimentos.

El principal exponente del trueque efectuado por los castellanos en estas zonas es el enclave de Mar Pequeña, donde los reyes ordenaron construir una torre, en el emplazamiento elegido por los señores de Canarias para el mismo fin. Las exportaciones consistían básicamente en productos alimenticios (trigo, cebada, miel harina, remiel), textiles y esclavos berberiscos. A estos productos autorizados o normalmente tolerados, hay que añadir otros rigurosamente prohibidos, como armas o plata. Los productos obtenidos a cambio eran esclavos negros, cueros, ámbar y oro. 